Cite this: Dalton Trans., 2014, 43, 6389

Received 15th September 2013, Accepted 4th February 2014

DOI: $10.1039 / c 3 d t 52543 k$

www.rsc.org/dalton

\section{Solid-state carbon-13 NMR and computational characterization of the N719 ruthenium sensitizer adsorbed on $\mathrm{TiO}_{2}$ nanoparticles $\uparrow$}

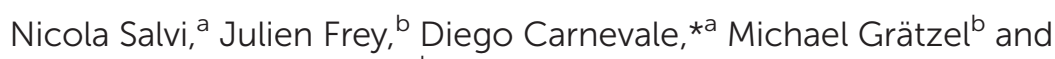 \\ Geoffrey Bodenhausen ${ }^{\mathrm{a}, \mathrm{c}, \mathrm{d}, \mathrm{e}}$
}

The ruthenium-containing sensitizing dye $\mathrm{N} 719$ grafted on $\mathrm{TiO}_{2}$ nanoparticles was investigated by solidstate NMR. The carbon resonances are assigned by means of ${ }^{13} \mathrm{C}$ cross-polarized dipolar dephasing experiments. DFT calculations of the carbon magnetic shielding tensors accurately describe the changes in chemical shifts observed upon grafting onto a titania surface via one or two carboxylic functions in the plane defined by the two isothiocyanate groups.

\section{Introduction}

Magic-angle spinning solid-state nuclear magnetic resonance (MAS-NMR) $^{1,2}$ is a powerful technique for exploring local environments in a variety of chemical systems. Regardless of the extent of disorder in the powder, MAS-NMR yields detailed isotropic and anisotropic information. The use of cross-polarization $^{3}$ (CP) allows investigation of low- $\gamma$ spins with low isotopic abundance, such as ${ }^{13} \mathrm{C}$ and ${ }^{29} \mathrm{Si}$.

This technique can provide useful information about systems that lack long-range order and cannot be easily characterized by diffraction techniques. In this context, we turned our interest to dyes adsorbed on nanoparticles of semiconducting materials such as $\mathrm{TiO}_{2}$. These systems constitute the basic premise of dye-sensitized solar cells (DSCs). ${ }^{4}$ The working principles of DSCs have been summarized in several reviews. ${ }^{5}$ The $\mathrm{TiO}_{2}$-dye interface is intrinsically disordered, and there is still a lack of understanding about the organization of the dye molecules on the surface. Solid-state NMR can contribute to address these issues and should help one to develop DSCs with better performance.

\footnotetext{
${ }^{a}$ Laboratoire de Resonance Magnétique Biomoléculaire, Institut des Sciences et Ingénierie Chimiques, Ecole Polytechnique Fédérale de Lausanne, EPFL, Batochime, 1015 Lausanne, Switzerland. E-mail: diego.carnevale@epfl.ch

${ }^{b}$ Laboratoire de Photonique et Interfaces, Institut des Sciences et Ingénierie Chimiques, Ecole Polytechnique Fédérale de Lausanne, EPFL, 1015 Lausanne, Switzerland

${ }^{c}$ Ecole Normale Supérieure, Département de Chimie, 75231 Paris Cedex 05, France ${ }^{d}$ UMR 7203, CNRS, Paris, France

${ }^{e}$ Université de Pierre-et-Marie Curie, Paris, France

$\dagger$ Electronic supplementary information (ESI) available. See DOI: $10.1039 / \mathrm{c} 3 \mathrm{dt} 52543 \mathrm{k}$
}

Solid-state NMR has been applied to the study of a variety of small molecules adsorbed on $\mathrm{TiO}_{2}$ such as water, ${ }^{6}$ urea, ${ }^{7}$ ethylene glycol ${ }^{8}$ and silicic acid. ${ }^{9}$ There have also been studies of larger species adsorbed on $\mathrm{TiO}_{2}$ such as organophosphorous chelators, ${ }^{10}$ melanine, ${ }^{11}$ styrene-butadiene rubber, ${ }^{12}$ tungstenophosphoric acid $^{13}$ or molybdenum complexes. ${ }^{14}$

We report here the characterization by MAS-NMR of carbon13 resonances of the common DSC sensitizing dye N719 adsorbed on $\mathrm{TiO}_{2}$. Attempts have been made to characterize the $\mathrm{TiO}_{2}-\mathrm{N} 719$ interface using vibrational, ${ }^{15-19}$ X-ray absorption (XAFS and XANES) ${ }^{20}$ and photoelectron spectroscopy ${ }^{21}$ techniques. These investigations indicate that the dye binds to the $\mathrm{TiO}_{2}$ surface through carboxylate groups, but their number is still a matter of debate. The carboxylate groups are anchored mainly via the formation of coordinative bonds with surface titanium species. While revisiting this archetypal example, we demonstrate how a combination of MAS-NMR and DFT calculations of magnetic shielding tensors can be used to gain information about interfacial systems relevant to solar-cell technologies.

\section{Results and discussion}

The structure of the sensitizing dye N719 ${ }^{22}$ with the conventional numbering of the carbon atoms is shown in Fig. 1. Two of the four carboxylic groups are deprotonated with tetrabutylammonium (TBA) as a counterion, and the two isothiocyanate groups (-NCS) are in the cis configuration. ${ }^{23}$ The ${ }^{13} \mathrm{C}$ resonances of N719 in solution have been assigned using $\left({ }^{1} \mathrm{H},{ }^{13} \mathrm{C}\right)$ heteronuclear correlation spectra (see Table 1 ). The differentiation between the sets of carbon atoms $\mathrm{C}(n)$ and $\mathrm{C}\left(n^{\prime}\right)$ that belong to aromatic rings carrying deprotonated and protonated carboxylate groups has been achieved using a ${ }^{1} \mathrm{H}$ ROESY spectrum. 


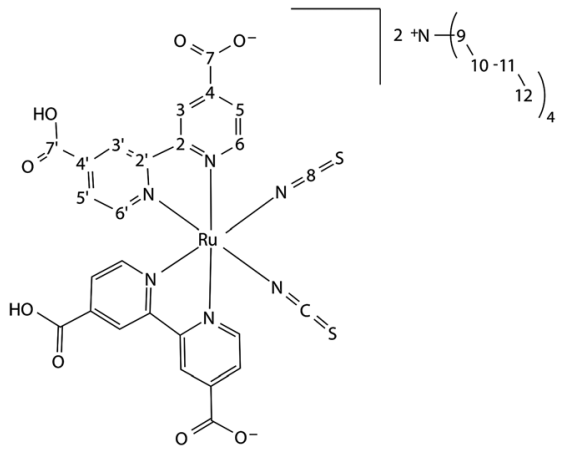

Fig. 1 Structure of the ruthenium-containing sensitizing dye N719 with conventional numbering of the carbon atoms.

Table 1 Assignment of resonances in solution-state ${ }^{13} \mathrm{C}$ spectra of the N719 dye dissolved in $\mathrm{CD}_{3} \mathrm{OD}$ (numbering of atoms as in Fig. 1). The right-most column reports the averages of the shifts of the pairs $C(n)$ and $C\left(n^{\prime}\right)$

\begin{tabular}{lll}
\hline $\begin{array}{l}{ }^{13} \mathrm{C} \text { chemical } \\
\text { shifts }(\mathrm{ppm})\end{array}$ & $\begin{array}{l}\text { Carbon } \\
\text { atom }\end{array}$ & $\begin{array}{l}\text { Averaged shifts of } \\
\text { pairs } \mathrm{C}(n) \text { and } \\
\mathrm{C}\left(n^{\prime}\right)(\mathrm{ppm})\end{array}$ \\
\hline 168.8 & $\mathrm{C}(7)$ & 168.7 \\
168.5 & $\mathrm{C}\left(7^{\prime}\right)$ & \\
160.5 & $\mathrm{C}\left(2^{\prime}\right)$ & 159.9 \\
159.3 & $\mathrm{C}(2)$ & \\
154.5 & $\mathrm{C}(6) \mathrm{H}$ & 154.0 \\
153.5 & $\mathrm{C}\left(6^{\prime}\right) \mathrm{H}$ & \\
144.1 & $\mathrm{C}(4)$ & \\
143.6 & $\mathrm{C}\left(4^{\prime}\right)$ & 143.9 \\
135.0 & $\mathrm{C}(8)$ & 126.0 \\
127.1 & $\mathrm{C}(5) \mathrm{H}$ & \\
126.5 & $\mathrm{C}\left(5^{\prime}\right) \mathrm{H}$ & \\
123.8 & $\mathrm{C}(3) \mathrm{H}$ & \\
123.6 & $\mathrm{C}\left(3^{\prime}\right) \mathrm{H}$ &
\end{tabular}

Fig. 2a shows, in black, a $\mathrm{CP}{ }^{13} \mathrm{C}$ MAS spectrum of the sensitizing dye N719 adsorbed on $\mathrm{TiO}_{2}$ powder. A dipolar dephased spectrum ${ }^{24}$ of the same system is shown in red. The dephasing interval was $\tau=60 \mu \mathrm{s}$. In this latter spectrum, carbons directly bound to protons lose intensity as a result of dipolar interactions whereas those without any direct proton neighbors retain roughly the same intensities. The isotropic shifts of proton-carrying and quaternary carbons appear in the same order as found in solution (Table 1), i.e., from left to right (high to low frequencies) the following order is found: $\mathrm{C}$, $\mathrm{C}, \mathrm{CH}, \mathrm{C}, \mathrm{C}, \mathrm{CH}, \mathrm{CH}$. The width of the resonances (FWHM ca. $6 \mathrm{ppm}$, i.e., ca. $600 \mathrm{~Hz}$ at $9.4 \mathrm{~T}$ ) can be attributed to the disorder that is expected for such interfacial species. This width prevents discrimination between the pairs of resonances $\mathrm{C}(n)$ and $\mathrm{C}\left(n^{\prime}\right)$ that one can observe in solution. Therefore, we have considered only chemical shifts averaged over these carbon pairs. Fig. $2 \mathrm{~b}$ shows a fit of the aromatic region of the spectrum shown in Fig. 1a, assuming that there are only seven different averaged shifts. The constituent peaks are shown in black. The agreement between the experimental spectrum and the fit, in red and blue, respectively, is very good. Fig. 2c shows the correlation between the solid-state chemical shifts resulting from the fit and the averaged chemical shifts observed in
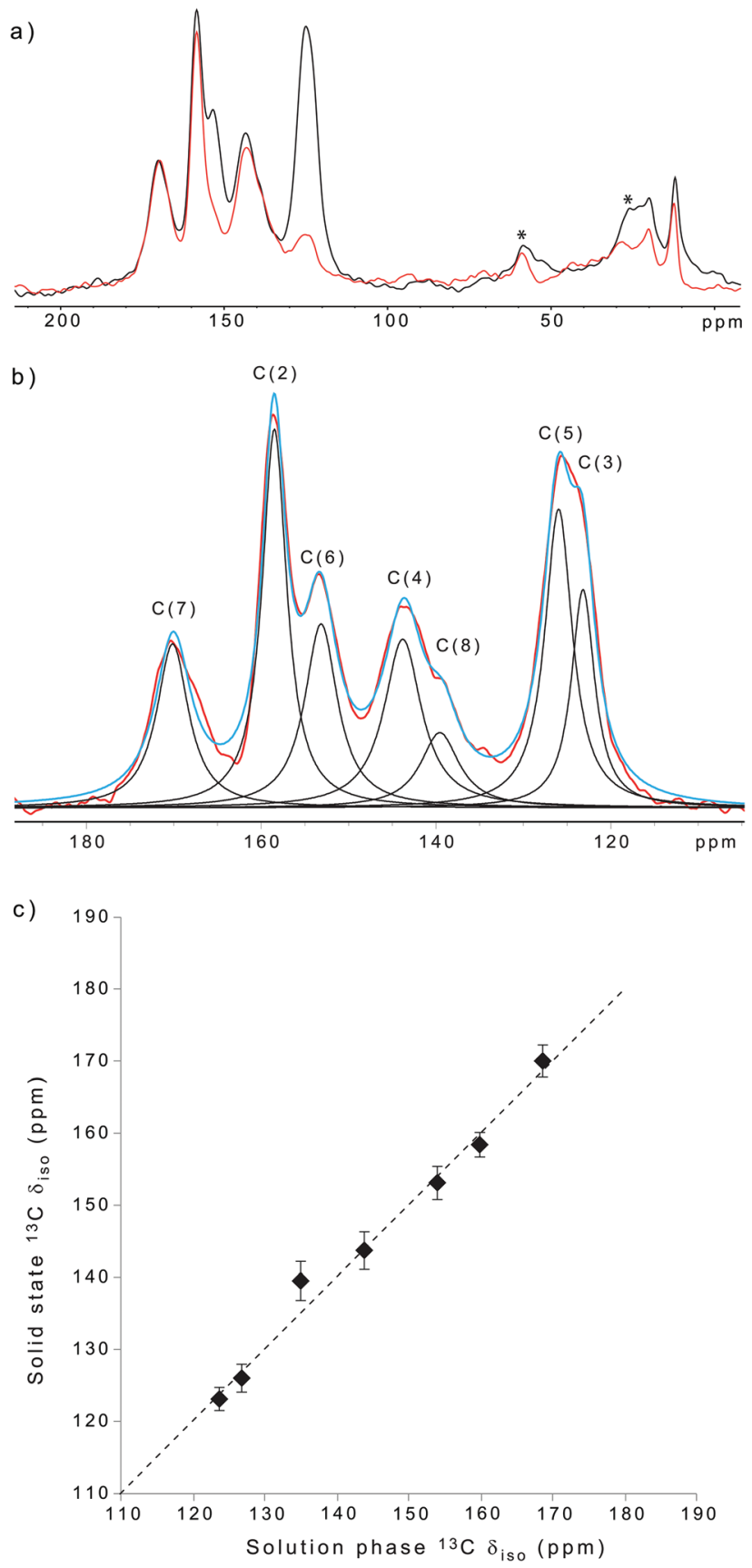

Fig. 2 (a) Magic-angle spinning (MAS) ${ }^{13} \mathrm{C}$ spectrum of a $\mathrm{TiO}_{2}$ powder sensitized with the $\mathrm{N} 719$ dye in a $3.2 \mathrm{~mm}$ rotor spinning at $10 \mathrm{kHz}$ at ca. $300 \mathrm{~K}$, enhanced by cross-polarization (CP) at $9.4 \mathrm{~T}(400 \mathrm{MHz}$ for protons). Overlaid in red: ${ }^{13} \mathrm{C}$ spectrum recorded with a dipolar dephasing interval $\tau=60 \mu$ s to attenuate signals of protonated carbons. (b) Simultaneous fitting of all 7 aromatic peaks of the spectrum in (a). The experimental spectrum is shown in red, the constituent peaks in black, and their sum that was fitted to the red spectrum in blue. (c) Correlation between experimental chemical shifts determined in the solid state by fitting with experimental chemical shifts in solution averaged over pairs $C(n)$ and $C\left(n^{\prime}\right)$.

solution. The vertical error bars of the solid-state shifts are determined by the line width of each ${ }^{13} \mathrm{C}$ signal estimated from the fit. The correlation obtained is quite good, with a 
Table 2 Assignment of resonances in solid-state ${ }^{13} \mathrm{C}$ spectra of the N719 dye adsorbed on $\mathrm{TiO}_{2}$ (numbering of atoms as in Fig. 1) assuming the same order of resonances as in Table 1. The isotropic shifts were derived by simultaneous fitting of all 7 peaks as shown in Fig. $2 \mathrm{~b}$

\begin{tabular}{ll}
\hline${ }^{13} \mathrm{C}$ Chemical shifts $(\mathrm{ppm})$ & Carbon atom \\
\hline 170.0 & $\mathrm{C}(7)$ \\
158.4 & $\mathrm{C}(2)$ \\
153.1 & $\mathrm{C}(6) \mathrm{H}$ \\
143.7 & $\mathrm{C}(4)$ \\
139.5 & $\mathrm{C}(8)$ \\
126.0 & $\mathrm{C}(5) \mathrm{H}$ \\
123.1 & $\mathrm{C}(3) \mathrm{H}$ \\
\end{tabular}

coefficient $R^{2}=0.985$. This suggests that the solution-state assignment can reasonably be transferred to the solid-state $\mathrm{TiO}_{2}$-grafted N719. The computational investigation presented in the following part of this study corroborates this assumption a posteriori. The assignment of the ${ }^{13} \mathrm{C}$ resonances of $\mathrm{N} 719$ in the solid state is shown in Table 2. It is worth mentioning that, once the solution-state assignment is transferred to the solidstate spectrum, C(8) is correctly predicted in the fit of Fig. $2 \mathrm{~b}$ as the less intense signal. This carbon is in fact present in the dye in a ratio of $1: 2$ compared to all other averaged carbon sites.

In order to confirm our solid-state assignments and postulate a mode of adsorption of the dye that is consistent with the observed chemical shifts, the magnetic shielding tensors of the sensitizing dye N719 have been calculated with DFT methods. The computational strategy that we adopted is depicted in Fig. 3a. The N719 structure was first optimized with the semi-empirical PM7 method as implemented in MOPAC2012. No counterions were included in this calculation. This geometry was then further optimized with the B3LYP/ $6-311++G(2 d, p)$ level of theory and a LANL2DZ pseudopotential for the Ru atom as implemented in Gaussian 09. This latter step was performed with and without inclusion of solvent effects in the calculation, so as to obtain data that can be related to the solution-state chemical shifts and to those of the $\mathrm{TiO}_{2}$-grafted system, which is not expected to contain any solvent molecules. We refer to the N719 structure optimized with inclusion of solvent effects as structure $\mathbf{0}$. The magnetic shielding tensors calculated on this latter structure with the GIAO method can be compared with those found in solution. In order to obtain analogous computational data to be compared with the solidstate grafted system a series of structures was generated so as to mimic the $\mathrm{N} 719-\mathrm{TiO}_{2}$ system. To this effect, the carboxylate functions of the DFT-optimized structure were functionalized with $\mathrm{Ti}(\mathrm{OH})_{4}$ groups. In order to explore different possible binding modalities, these functionalizations were carried out for one, two, or three carboxylate functions, both in equatorial and axial positions with respect to the plane defined by the two -NCS groups. We did not consider two out-of-plane functionalizations as these could not mimic binding onto a planar $\mathrm{TiO}_{2}$ surface. We refer to these structures as $m_{p}$, where $m$ is the number of $\mathrm{Ti}(\mathrm{OH})_{4}$ used to functionalize the carboxylate groups, and $p$ is a positional index, which can be either in or out, indicating in-plane or out-of-plane functionalizations, respectively, with respect to the plane defined by the two -NCS groups. Following this nomenclature, we have studied structures $\mathbf{1}_{\text {in }}, \mathbf{1}_{\text {out }}, \mathbf{2}_{\text {in }}, \mathbf{2}_{\text {out }}$ and $\mathbf{3}$. It is worth mentioning at this point that the five structures considered have generally different numbers of atoms and charges, and are therefore not directly comparable in terms of energy. This is a consequence of (i) the number of $\mathrm{Ti}(\mathrm{OH})_{4}$ groups used in the functionalization and (ii) whether the functionalization involves a $\mathrm{COO}^{-}$ or a $\mathrm{COOH}$ group. The functionalization of a $\mathrm{COO}^{-}$group results in the elimination of an $\mathrm{OH}^{-}$so that the final system has a total charge -1 (structures $\mathbf{1}_{\text {out }}, \mathbf{2}_{\text {out }}$ and 3 ). In contrast, the functionalization of a $\mathrm{COOH}$ group results in the elimination of $\mathrm{H}_{2} \mathrm{O}$, thus leaving a total charge of -2 for the whole system (structures $\mathbf{1}_{\text {in }}$ and $\boldsymbol{2}_{\text {in }}$ ). The geometries of all five solidstate structures generated according to the above-mentioned computational scheme are shown in Fig. 3b. Fig. 4a shows the correlations between the experimental ${ }^{13} \mathrm{C}$ chemical shifts and those calculated with the computational approach adopted in this study. In this figure, the experimental solution-state shifts are correlated with those calculated for structure $\mathbf{0}$ whereas the experimental solid-state shifts are correlated with those calculated for the five functionalized solid-state structures, i.e., $\mathbf{1}_{\mathrm{in}}$, $\mathbf{1}_{\text {out }}, \mathbf{2}_{\text {in }}, \mathbf{2}_{\text {out }}$ and $\mathbf{3}$. The vertical error bars are the same as in Fig. 2a and are only shown, for the sake of clarity, for data points that deviate significantly from the dashed line of ideal correlations. Within the set of structures, which are meant to mimic the grafted system, $C(7)$ is the one which experiences the largest range of shifts as the numbers of functionalizations grows. Another carbon which shows a substantial spread of shifts is $\mathrm{C}(4)$. This is understandable in structural terms, since these two carbons are closest to the Ti centers, only one and two bonds apart, respectively. The spread of shifts due to the functionalizations of the carboxylate groups for these two carbons is highlighted by black arrows in Fig. 4a. All other carbon shifts, in contrast, are barely affected by the $-\mathrm{Ti}(\mathrm{OH})_{3}$ functionalizations. If one considers instead the changes in shifts observed when one moves from the solution state to the grafted solid-state system, the carbon experiencing the largest change in chemical shift is $\mathrm{C}(8)$. In order to investigate this observation, we have mapped the electrostatic potential on the electron density isosurface of the six structures considered (ESI, Fig. S1 $\dagger$ ). These maps show that the -NCS groups, along with the $-\mathrm{COO}^{-}$, are the most negatively charged of the whole molecular system. Hence, larger changes in shifts are expected when electrostatic interactions change (either due to solvent molecules in solution, or to other N719 molecules and/or counterions in the solid state). The shift changes of $\mathrm{C}(8)$ when comparing the solution- and solid-state are highlighted by a red arrow in Fig. 4a.

Both these aspects, i.e., the effect of different functionalizations on the solid-state shifts and the changes induced by the transition from the solution to the grafted system, can be more easily appreciated in Fig. 4b, where both experimental and calculated differences observed upon binding are plotted for individual carbon sites. In this figure, the experimental differences in chemical shifts $\left(\delta_{\exp }^{\text {solution }}-\delta_{\exp }^{\text {solid }}\right)$ are shown by red dots. All 
a)

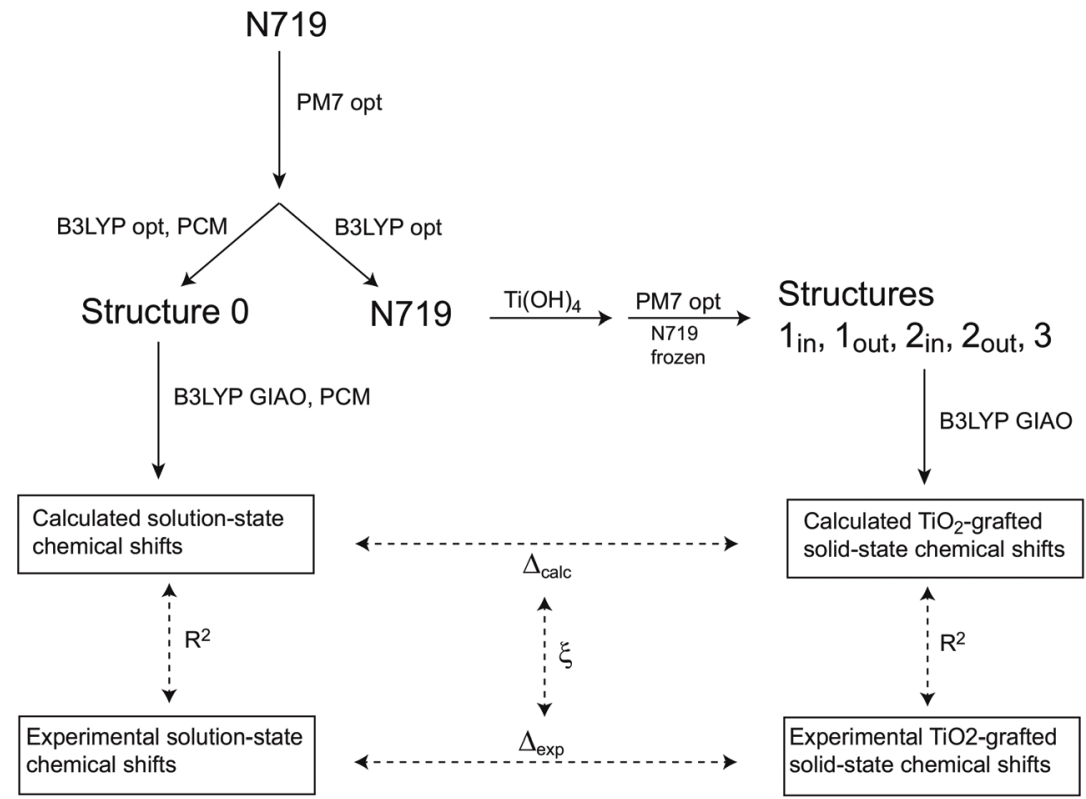

b)

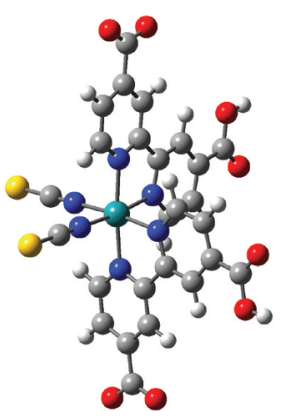

0

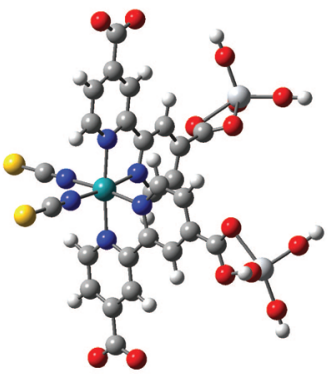

$2_{\text {in }}$

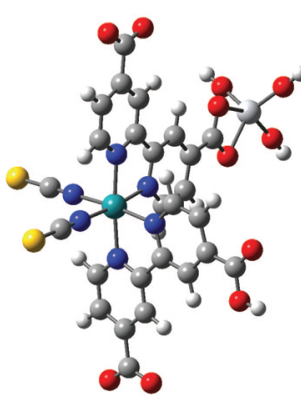

$1_{\text {in }}$

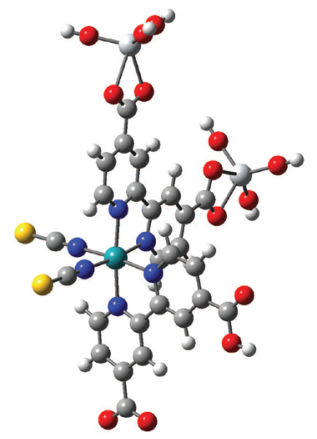

$2_{\text {out }}$
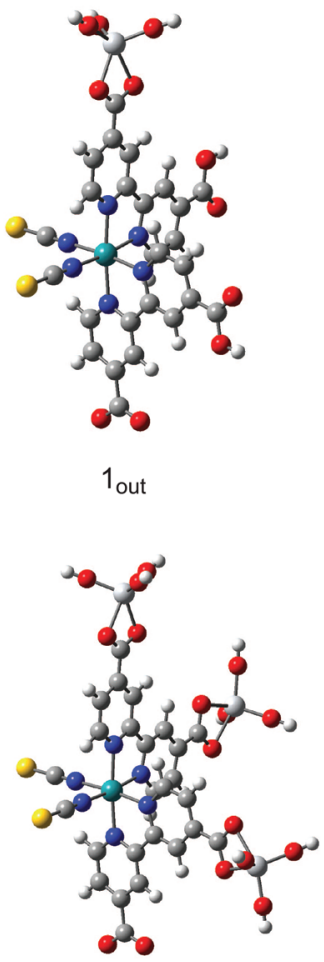

3

Fig. 3 (a) Computational procedure adopted in this study. The dashed arrows indicate comparisons between experiments and calculations using $R^{2}$ coefficients, while the descriptor $\xi$ defined in the text allows one to compare experimental and calculated changes in ${ }^{13} \mathrm{C}$ shifts between the solution and solid states. (b) Structures generated by the computational scheme in (a).

the other data points refer instead to chemical shift differences calculated with DFT methods ( $\delta_{\text {calc }}^{\text {solution (structure o) }}-$ $\delta_{\text {calc }}^{\text {solid (structure } i)}$, where the index $i$ covers all five functionalized structures, i.e., $\mathbf{1}_{\mathrm{in}}, \mathbf{1}_{\mathrm{out}}, \mathbf{2}_{\mathrm{in}}, \mathbf{2}_{\mathrm{out}}$ and $\mathbf{3}$ ). It is clear in this graph that (i) $\mathrm{C}(8)$ experiences the largest changes in chemical shift between the solution and the solid, both on the experimental and the computational level, and (ii) C(7) and C(4) are most strongly influenced by the grafting process. These two features are highlighted by red and black vertical arrows, respectively, which have the same meaning as in Fig. 4a. The calculated profile resulting from structure $\boldsymbol{1}_{\text {in }}$ (blue continuous line) seems to reproduce the changes in experimental chemical 


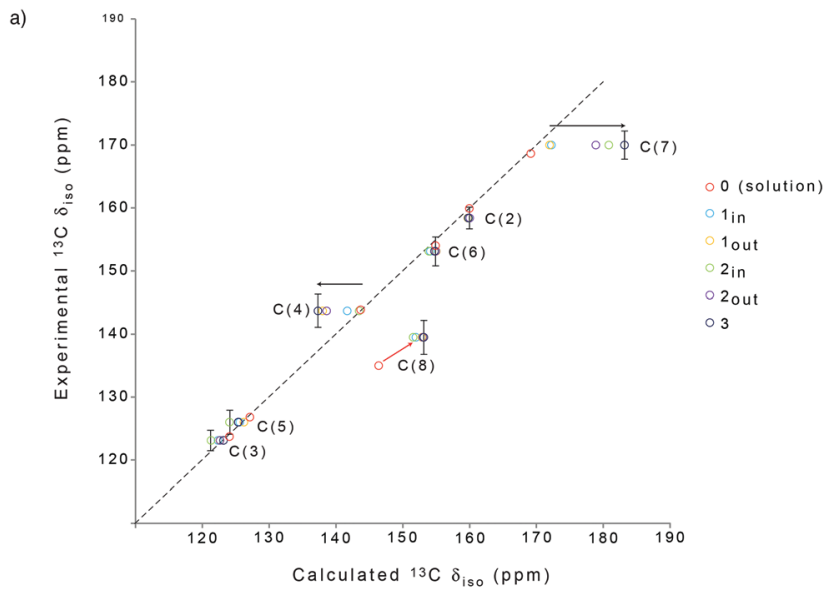

b)

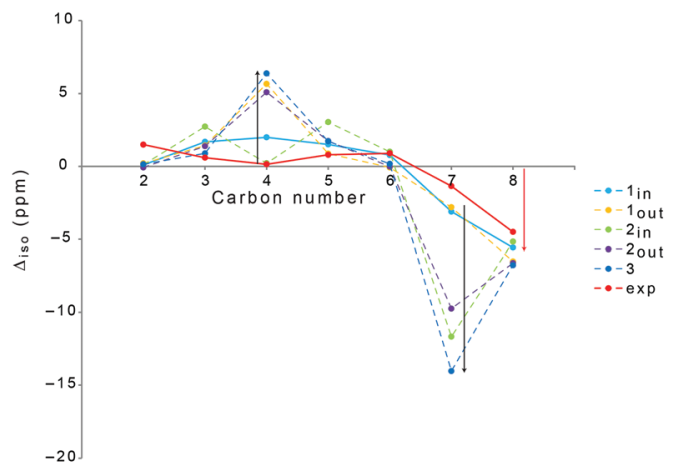

c)

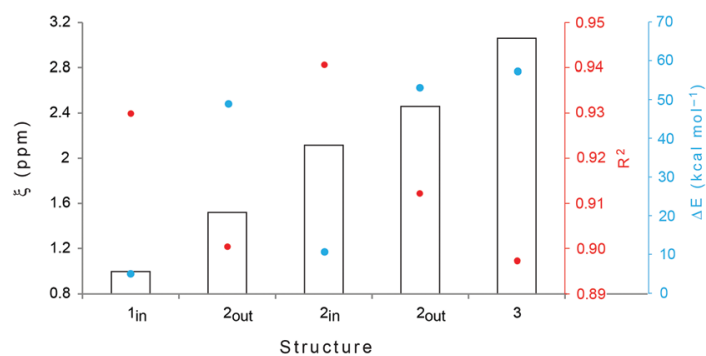

Fig. 4 (a) Correlations between experimental and calculated ${ }^{13} \mathrm{C}$ shifts for the six structures of N719 shown in Fig. 3b. (b) Differences between solution- and solid-state chemical shifts. (c) Histogram showing the descriptor $\xi$, the correlation coefficient $R^{2}$ and the heat of formation $\Delta E$, in black, red and blue, respectively, obtained for the five solid structures considered in this study. Structures $\boldsymbol{1}_{\text {in }}$ and $\boldsymbol{2}_{\text {in }}$ have a total charge -2 whereas all others have a total charge -1 . Structure $1_{\text {in }}$ results in the smallest mismatch $\xi$ with the experimental data and the smallest energy of formation $\Delta E$. Structure $\boldsymbol{2}_{\text {in }}$ affords the best correlation coefficient $R^{2}$ with the experimental data.

shifts (red continuous line) quite well. In order to evaluate and compare this series of models of the grafted structures in terms of calculated and experimentally-observed chemical shift changes between the solution and the $\mathrm{TiO}_{2}$-grafted system, we find it convenient to define the descriptor $\xi=$ $n^{-1} \sum_{i}\left|\Delta_{i}^{\text {calc }}-\Delta_{i}^{\text {exp }}\right|$, where $n$ is the number of carbons considered, i.e., 8 in our case, $i$ is the carbon number (as shown in Fig. 1) and $\Delta_{i}=\delta_{i}^{\text {solution }}-\delta_{i}^{\text {solid }}$. This descriptor evaluates the quality of the profiles of Fig. $4 \mathrm{~b}$ for a given geometry and is minimized when the calculated changes in chemical shift upon binding match those observed experimentally. The descriptor can be interpreted as an average chemical shift mismatch associated with each carbon site that a proposed structure would produce when compared to the real system. Fig. 4c shows the descriptor $\xi$ obtained for the five structures considered. The $\mathbf{1}_{\text {in }}$ geometry clearly results in a minimal mismatch with the experimental data. In the same graph, in red, the coefficient $R^{2}$ of the correlations shown in Fig. 4a are also shown. The structures $\boldsymbol{2}_{\text {in }}$ and $\mathbf{1}_{\text {in }}$ produce the best correlations with the experimental shifts whereas out-of-plane binding modes are associated with lower correlations.

We also considered the heat of formation of all species involved in the functionalizations as calculated using MOPAC2012 with the semi-empirical PM7 method. The overall energy change due to the functionalizations can be expressed as $\Delta E=\sum_{i} E_{i}^{\text {Prod }}-\sum_{j} E_{j}^{\text {Reag }}$, where $i$ indicates the different product species of the reaction, i.e., structure $\mathbf{0}$ and the appropriate number of $\mathrm{Ti}(\mathrm{OH})_{4}$ groups, and $j$ indicates the relevant reagent species of the reaction, i.e., $\mathbf{1}_{\text {in }}, \mathbf{1}_{\text {out }}, \boldsymbol{2}_{\text {in }}, \boldsymbol{2}_{\text {out }}, \mathbf{3}$ and the appropriate number of $\mathrm{H}_{2} \mathrm{O}$ or $\mathrm{OH}^{-}$groups (the latter two for in-plane and out-of-plane functionalizations, respectively). The results are shown in blue in Fig. 4c. It is particularly evident that, when the overall heat of formation is considered, the inplane functionalization is favored (or rather less disfavored, given that all $\Delta E>0$ ) than the out-of-plane functionalization.

For the sake of completeness, titania functionalizations analogous to those performed on the carboxylate groups were also carried out on either one or both sulfur centres. The magnetic shifts obtained in these cases, however, poorly correlate with the experimental data, with coefficients $R^{2}=0.478$ and 0.272 , respectively, and $\xi=9.0$ and $15.1 \mathrm{ppm}$, respectively. A grafting mode of the sensitizing dye N719 onto a titania surface via the isothiocyanate groups seems therefore to be incompatible with our computational models.

In all structures functionalized in silico (correlated with experimental solid-state shifts) as well as structure $\mathbf{0}$ (correlated with experimental solution-state shifts), C(8) always lies systematically off the diagonal in Fig. 4a. However, Fig. 2a shows a remarkably good correlation between the experimental solid- and solution-state shifts. This indicates that, whether in solution or grafted onto $\mathrm{TiO}_{2}$ nanoparticles, our calculations fail to describe the environment of carbon $\mathrm{C}(8)$ adequately. As previously stated, the electrostatic potentials mapped on the electron density isosurfaces shown in the ESI (Fig. S1†) clearly highlight that the -NCS group, along with the formally charged $-\mathrm{COO}^{-}$, is the most negatively charged group in the whole molecular system. Clearly, (i) the presence of interactions such as H-bonds with solvent molecules (which are not explicitly taken into account in the solvation model used for structure $\mathbf{0}$ ) or (ii) the presence of neighboring N719 dye molecules and/or other counterions (which are not included in the structures we considered to mimic the grafted system) will result in a mismatch between the experimental and calculated shifts for the $\mathrm{C}(8)$ carbon. In order to further investigate the 
effects of the solvent or other species on these mismatches, a series of calculations of the chemical shifts was performed on structure $\mathbf{0}$, without a solvent, with a solvent, and by including one or two $\mathrm{Na}^{+}$cations aligned with the NCS vector, at a distance $4.07 \AA$ from the $\mathrm{S}$ atom, equal to the sum of the van der Waals radii of the $\mathrm{S}$ and $\mathrm{Na}$ atoms, so as to mimic the presence of other cationic species in solution. The corresponding correlations are shown in the ESI (Fig. S2 $\dagger$ ). A very strong dependence of the shift of $\mathrm{C}(8)$ on the environment is clearly highlighted. This seems to confirm that the mismatch between our calculated and experimental shifts of $\mathrm{C}(8)$, both for the solution and the $\mathrm{TiO}_{2}$-grafted structures, can be reasonably ascribed to the insufficient description of the surroundings of this environment in our computational models. Nevertheless, this shortcoming appears systematically in both the solution-state structure (0) and the solid-state structures $\left(\mathbf{1}_{\text {in }}, \mathbf{1}_{\text {out }}, \boldsymbol{2}_{\text {in }}, \mathbf{2}_{\text {out }}\right.$ and 3 ). This is proven by the fact that the inclusion of solvent and of cationic species in the calculation moves the data points of $\mathrm{C}(8)$ (Fig. $\mathrm{S} 2 \dagger)$. As can be appreciated in Fig. 2a, this displacement is similar for $\mathrm{C}(8)$ for all structures considered. In fact, the red arrow in Fig. 4a lies close to the diagonal. Therefore, although these mismatches affect our $R^{2}$ coefficients, they do not interfere significantly with our ranking of the structures in terms of agreement with the experimental data as they simply result in lowering all $R^{2}$ coefficients. Furthermore, being based on the differences of chemical shift changes between the solution and solid states, our descriptor $\xi$ is immune to such errors which occur in substantially equal amounts both in the solution structure (0) and in the solid-state structures $\left(\mathbf{1}_{\text {in }}, \mathbf{1}_{\text {out }}, \mathbf{2}_{\text {in }}, \mathbf{2}_{\text {out }}\right.$ and $\left.\mathbf{3}\right)$. In conclusion, the chemical shift changes that are observed and predicted for $\mathrm{C}(8)$ when moving from solution to the solid-state grafted system (red arrow in Fig. 4a) can be ascribed to the effect of binding of the N719 onto a titania surface via carboxylic functions in the -NCS plane rather than to the removal of the solvent.

Upon grafting, a fraction of the TBA is left in solution, as may be appreciated from the ${ }^{1} \mathrm{H}$ spectrum of Fig. S3 (ESI $\dagger$ ). The signal integrals show clearly that there is excess TBA after adding $\mathrm{TiO}_{2}$ powder, thus proving that, upon grafting, some TBA remains in solution. A further proof of the removal of TBA is given by the FTIR spectrum shown in the ESI (Fig. S4 $\dagger$ ), which highlights the absence of a characteristic aliphatic adsorption band. The FTIR spectrum also proves that the -NCS groups are still present in the grafted system, with an adsorption band in full agreement with previously reported data.

\section{Conclusions}

The carbon environments of the ruthenium-containing dye N719 adsorbed on $\mathrm{TiO}_{2}$ nanoparticles have been characterized by means of solid-state MAS NMR. A computational investigation carried out for simplified systems nicely describes the changes in chemical shifts experienced by the carbon resonances upon grafting onto a titania surface. Amongst the binding modes considered in our in silico investigation, binding via one or two carboxylic functions in the plane containing the two -NCS groups produces the best agreement with the experimental data. This is suggested by (i) the $R^{2}$ correlation coefficients between experimental and calculated ${ }^{13} \mathrm{C}$ chemical shifts, (ii) the changes of chemical shifts between solution and solid-state grafted systems considered through the descriptor $\xi$ defined ad hoc in this study and (iii) by the heat of formation of the bound structures calculated with the semi-empirical PM7 method. A hypothetical grafting mode with carboxylate groups in axial positions does not match the solid-state shifts predicted by our computational investigation. We shall further explore the use of solid-state NMR spectroscopy and computational methods to study the arrangement of dyes, their aggregation, the qualitative and quantitative effects of coadsorbents, and other features of adsorption of dyes on $\mathrm{TiO}_{2}$.

\section{Experimental section}

The solid-state NMR spectra were acquired with a Bruker Avance-II spectrometer equipped with a wide-bore $9.4 \mathrm{~T}$ magnet, operating at a Larmor frequencies $\omega_{0} / 2 \pi=400.0$ and 100.6 MHz for ${ }^{1} \mathrm{H}$ and ${ }^{13} \mathrm{C}$, respectively. A triple-channel MAS probe designed for low-temperature DNP was used at $c a$. $300 \mathrm{~K}$, with samples packed in $3.2 \mathrm{~mm} \mathrm{ZrO}_{2}$ rotors. The spinning rate was $\omega_{\text {rot }} / 2 \pi=10 \mathrm{kHz}$. The radiofrequency field strength of both ${ }^{1} \mathrm{H} 90^{\circ}$ and ${ }^{13} \mathrm{C}^{\circ} 180^{\circ}$ pulses was $\omega_{1} / 2 \pi=100$ $\mathrm{kHz}$, whereas those used for cross polarization were $\omega_{1} / 2 \pi=70$ and $50 \mathrm{kHz}$ for ${ }^{1} \mathrm{H}$ and ${ }^{13} \mathrm{C}$, respectively, with a contact time of $4 \mathrm{~ms}$. The amplitude of the ${ }^{1} \mathrm{H}$ pulse was ramped from 90 to $100 \%$ during CP. Recovery delays varied between 0.6 and $1 \mathrm{~s}$. The ${ }^{13} \mathrm{C}$ spectra were referenced to TMS using adamantane as an external reference, setting $38.4 \mathrm{ppm}$ for the most deshielded peak. The numerical fit of Fig. $2 \mathrm{~b}$ was performed with the software dmfit. $^{25}$

All structures considered in this study were optimized by a combination of the semi-empirical PM7 method implemented in MOPAC2012 26 and DFT B3LYP ${ }^{27,28}$ hybrid functionals employing the $6-311++\mathrm{G}(2 \mathrm{~d}, \mathrm{p})$ basis set on $\mathrm{H}, \mathrm{C}, \mathrm{O}, \mathrm{N}$ and $\mathrm{S}$ centres, and the LANL2DZ ${ }^{29-31}$ effective-core potential for the $\mathrm{Ru}$ and $\mathrm{Ti}$ centres, as implemented in Gaussian09 Revision A.01. ${ }^{32}$ These optimized geometries were then used for the calculations of the magnetic shielding tensors with the GIAO $\operatorname{method}^{33,34}$ at the same level of theory of the DFT optimizations. Solvation, when used, was taken into account with the PCM method. ${ }^{35}$ The calculated shifts were referenced to TMS, either with or without solvation effects. The calculations were performed at the EPFL on an Ubuntu Linux 12.04 platform equipped with eight $2.27 \mathrm{GHz}$ CPUs.

The samples were prepared using the following procedure. A sample of the sensitizing dye N719 $\left(59.4 \mathrm{mg}=5.0 \times 10^{-5}\right.$ mol) was dissolved in a $1: 1$ acetonitrile-methanol mixture to obtain $100 \mathrm{~mL}$ of a $5 \times 10^{-4} \mathrm{M}$ solution. $\mathrm{TiO}_{2}$ powder $(25 \mathrm{mg})$ 
was immersed in this solution and left overnight in the dark under continuous stirring. The nanoparticles were then filtered off, rinsed with acetonitrile and methanol successively and dried under vacuum. The acetonitrile and methanol were of analytical grade quality (Merck). The sensitizing dye N719 was purchased from Dyesol and anatase $\mathrm{TiO}_{2}$ P25 powder $(25 \mathrm{~nm}$ particle size and $50 \mathrm{~m}^{2} \mathrm{~g}^{-1}$ surface area) from Degussa (Evonik).

\section{Acknowledgements}

The authors would like to thank Martial Rey for technical assistance and Dr Daniel F. Jana for constructive discussions. This work was supported by the Swiss National Science Foundation (SNSF), the Swiss Commission for Technology and Innovation (CTI), the EPFL, and Bruker Biospin AG, Fällanden $(\mathrm{ZH})$, Switzerland. MG thanks the European Research Council (ERC) for funding of his work under the MESOLIGHT Advanced Research grant no. 247404.

\section{References}

1 E. R. Andrew, A. Bradbury and R. G. Eades, Nature, 1958, $182,1659$.

2 E. R. Andrew, A. Bradbury and R. G. Eades, Nature, 1959, 183, 1802.

3 A. Pines, M. G. Gibby and J. Waugh, J. Chem. Phys., 1973, 59, 569.

4 B. O’Regan and M. Grätzel, Nature, 1991, 353, 737.

5 A. Hagfeldt, G. Boschloo, L. C. Sun, L. Kloo and H. Pettersson, Chem. Rev., 2010, 110, 6595.

6 A. Y. Nosaka, T. Fujiwara, H. Yagi, H. Akutsu and Y. Nosaka, J. Phys. Chem. B, 2004, 108, 9121.

7 E. A. Reyes-Garcia, Y. Sun, K. Reyes-Gil and D. Raftery, J. Phys. Chem. C, 2007, 111, 2738.

8 T. Tachikawa, Y. Takai, S. Tojo, M. Fujitsuka, H. Irie, K. Hashimoto and T. Majima, J. Phys. Chem. B, 2006, 110, 13158.

9 P. J. Swedlund, Y. Song, Z. D. Zujovic, M. K. Nieuwoudt, A. Hermann and G. J. McIntosh, J. Colloid Interface Sci., 2012, 368, 447.

10 M. Becuwe, P. Rouge, C. Gervais, M. Courty, A. DassonvilleKlimpt, P. Sonnet and E. Baudrin, J. Colloid Interface Sci., 2012, 388, 130.

11 T.-J. Park, J. Kim, T.-K. Kim, H.-M. Park, S.-S. Choi and Y. Kim, Bull. Korean Chem. Soc., 2008, 29(12), 2459.

12 T. M. Arantes, K. V. Leao, M. I. B. Tavares, A. G. Ferreira, E. Longo and E. R. Camargo, Polym. Test., 2009, 28, 490.

13 J. C. Edwards, C. Y. Thiel, B. Benac and J. F. Knifton, Catal. Lett., 1998, 51, 77.

14 C. A. Paez, N. J. Castellanos, F. O. Martinez, F. Ziarelli, G. Agrifoglio, E. A. Paez-Mozo and H. Arzoumaian, Catal. Today, 2008, 133, 619.

15 K. S. Finnie, J. R. Bartlett and J. L. Woolfrey, Langmuir, 1998, 14, 2744.
16 C. P. Leon, L. Kador, B. Peng and M. Thelakkat, J. Phys. Chem. B, 2006, 10, 8723.

17 K. Murakoshi, G. Kano, Y. Wada, S. Yanagida, H. Miyazaki, M. Matsumoto and S. Murasawa, J. Electroanal. Chem., 1995, 396, 27.

18 M. K. Nazeeruddin, R. Humphry-Baker, P. Liska and M. Grätzel, J. Phys. Chem. B, 2003, 107, 8981.

19 M. K. Nazeeruddin, S. M. Zakeeruddin, R. Humphry-Baker, M. Jirousek, P. Liska, N. Vlachopoulos, V. Shklover, C. H. Fischer and M. Grätzel, Inorg. Chem., 1999, 38, 6298.

20 Y. V. Zubavichus, Y. L. Slovokhotov, M. K. Nazeeruddin, S. M. Zakeeruddin, M. Grätzel and V. Shklover, Chem. Mater., 2002, 14, 3556.

21 E. M. J. Johansson, M. Hedlund, H. Siegbahn and H. Rensmo, J. Phys. Chem. B, 2005, 109, 22256.

22 M. K. Nazeeruddin, F. De Angelis, S. Fantacci, A. Selloni, G. Viscardi, P. Liska, S. Ito, T. Bessho and M. Grätzel, J. Am. Chem. Soc., 2005, 127, 16835.

23 V. Shklover, Y. E. Ovchinnikov, L. S. Braginsky, S. M. Zakeeruddin and M. Grätzel, Chem. Mater., 1998, 10, 2533.

24 S. J. Opella and M. H. Frey, J. Am. Chem. Soc., 1979, 101, 5854.

25 D. Massiot, F. Fayon, M. Capron, I. King, S. Le Calvé, B. Alonso, J.-O. Durand, B. Bujoli, Z. Gan and G. Hoatson, Magn. Reson. Chem., 2002, 40, 70.

26 MOPAC2012, J. J. P. Stewart, Stewart Computational Chemistry, Version 13.073W web: http://Openmopac.Net

27 A. D. Becke, J. Chem. Phys., 1993, 98, 5648.

28 C. Lee, W. Yang and R. G. Parr, Phys. Rev. B: Condens. Matter Mater. Phys., 1988, 37, 785.

29 P. J. Hay and W. R. Wadt, J. Chem. Phys., 1985, 82, 270.

30 W. R. Wadt and P. J. Hay, J. Chem. Phys., 1985, 82, 284.

31 P. J. Hay and W. R. Wadt, J. Chem. Phys., 1985, 82, 299.

32 M. J. Frisch, G. W. Trucks, H. B. Schlegel, G. E. Scuseria, M. A. Robb, J. R. Cheeseman, G. Scalmani, V. Barone, B. Mennucci, G. A. Petersson, H. Nakatsuji, M. Caricato, X. Li, H. P. Hratchian, A. F. Izmaylov, J. Bloino, G. Zheng, J. L. Sonnenberg, M. Hada, M. Ehara, K. Toyota, R. Fukuda, J. Hasegawa, M. Ishida, T. Nakajima, Y. Honda, O. Kitao, H. Nakai, T. Vreven, J. A. Montgomery Jr., J. E. Peralta, F. Ogliaro, M. Bearpark, J. J. Heyd, E. Brothers, K. N. Kudin, V. N. Staroverov, R. Kobayashi, J. Normand, K. Raghavachari, A. Rendell, J. C. Burant, S. S. Iyengar, J. Tomasi, M. Cossi, N. Rega, J. M. Millam, M. Klene, J. E. Knox, J. B. Cross, V. Bakken, C. Adamo, J. Jaramillo, R. Gomperts, R. E. Stratmann, O. Yazyev, A. J. Austin, R. Cammi, C. Pomelli, J. W. Ochterski, R. L. Martin, K. Morokuma, V. G. Zakrzewski, G. A. Voth, P. Salvador, J. J. Dannenberg, S. Dapprich, A. D. Daniels, Ö. Farkas, J. B. Foresman, J. V. Ortiz, J. Cioslowski and D. J. Fox, Gaussian 09, Revision A.01, Gaussian, Inc., Wallingford CT, 2009. 33 D. Zeroka and H. F. Hameka, J. Chem. Phys., 1966, 45, 300. 34 R. Ditchfield, J. Chem. Phys., 1972, 56, 5688.

35 E. Carcès, B. Mennucci and J. Tomasi, J. Chem. Phys., 1997, 107, 3032. 